\title{
Information System Quality: Managers Perspective
}

\author{
Sarah Aouhassi, Mostafa Hanoune \\ Laboratory of Information Technology and modeling, \\ Faculty of Sciences Ben M'Sik, Hassan II University of Casablanca \\ B.P. 7955 Sidi Othmane, Casablanca, Morocco
}

\begin{abstract}
To evaluate Information System Quality (ISQ) quantitatively, a model was constructed based on sub-models related to the five Information System (IS) components, namely, Human Resources, Hardware, Software and application, Procedure and Data, and all IS players perspectives are considered who are: Managers, Technical Staff, Functional Staff and Users. This paper focuses on the survey designed for managers in order to form the variable indicators from variable questions, via appropriate formulas in the first place, and to analyze data collected from IS managers of the Moroccan universities in the second one. This approach will allow diagnosing precisely the malfunctioning areas on ISQ by emphasizing on the components with less quality level. It will also enable making comparison of ISQ on different organizations with the mean of standardized values.
\end{abstract}

Keywords-Information system; quality; managers; measurement indicator; university

\section{INTRODUCTION}

The first thing one think about when approaching ISQ field is software quality with all its inherent models and practices, characteristics and sub-characteristics, factors and criteria, metric and measure, $[5 ; 6 ; 9 ; 12 ; 13 ; 14 ; 15 ; 19]$. However, IS is defined as an organized set of resources (human, software, hardware, procedures and data) which allow to collect, sort, classify, treat and transmit information on working environment, therefore, IS quality should be a reflection of the quality level of all its components [22].

The literature review on the field of ISQ shows a variety of models that treat this problem; each one is focusing on a number of features with a multitude of metrics. However a common limitation rises, firstly, all models mix up ISQ with Software and Application Quality (SAQ), secondly, the surveys used to collect data are designed basically for technical staff only.

On previous work [1], a global model was defined and named ISysQ with a set of measuring indicators covering all IS attributes for each component (Fig. 1) and customized surveys were constructed and adapted to the respective IS intervening (IS managers, technical staff, functional staff and users). The global model contains 25 indicators as mentioned in Fig. 1, but not all these indicators concern at the same time every IS player.

The focus of this study is the managers' survey [20] and their perspectives about ISQ [11]. The IS managers are the party who is meant to ensure quality of IS in any organization. In fact, manager is by definition "An individual who is in charge of a certain group of tasks, or a certain subset of a company. A manager often has a staff of people who report to him or her. Certain departments within a company designate their managers to be line managers, while others are known as staff managers, depending upon the function of the department. (http://www.businessdictionary.com.). The definition of quality by ISO 8402-1986 standard is "the totality of features and characteristics of a product or service that bears its ability to satisfy stated or implied needs". Crossing these definitions with the one of IS, it will be implied that IS managers are the players who are supposed to have inclusive information about ISQ.

This study aims to give numerical values instead of qualitative description to IS indicators and components [2]. The numerical values attributed to variable questions that constitute the survey are aggregated in variable indicators [16] by component, giving rise to summary values of ISQ components. This approach allows to highlight strengths and weaknesses of each IS component in order to provide later corrective measures. ISQ quantification will allow thereby an objective comparison of several organizations [7] in detailed way by going down to the lowest level of the hierarchical structure of ISysQ which are indicators.

The ISysQ model have five dimensions related to the five IS components. In this contribution, a particular focus will be on the Human Resources Quality and Data Quality dimensions. The same approach can be applied to the other ones.

In the following sections, first the theoretical model of ISQ with 25 indicators is developed. Then, the specification of the model adapted for IS Managers is performed. After that, a presentation of the research methodology including the description and implementation of the study on one hand and the aggregation of the variables questions into variable indicators on the other hand is realized. Next, the analysis and results of the data collected is presented. Finally, the paper concludes with a discussion of the findings and directions for future research.

\section{THEORETICAL BACKGROUND AND CONTEXT OF IS QUALIFICATION}

The literature review in the field of IS quality has shown a major deficiency related to the IS components other than software and applications [10; 19], while having an IS quality means that all its components have a certain quality level.

The hybrid model adopted [1] is composed of five submodels as shown in Fig. 1. 


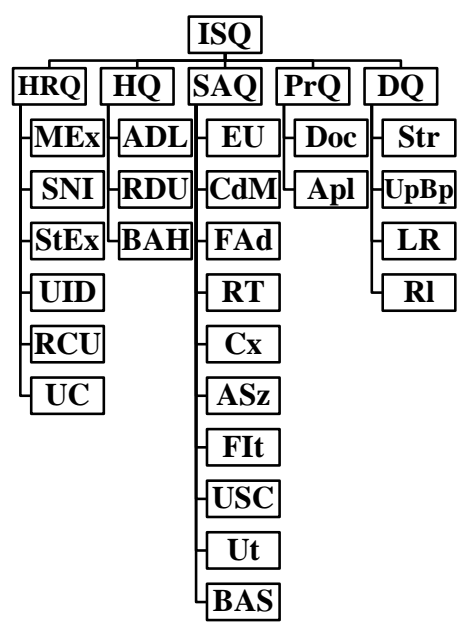

Fig. 1. IS Quality Model Indicators.

Among the 25 indicators that constitute the ISQ model, 22 are related to the IS Managers as mentioned in Fig. 2, reaching thereby the maximum of indicators that can have an IS intervening sub-model.

The indicators (gathered by IS component) which don't concern IS Managers are:

- HRQ: User competency (UC).

- HQ: Average duration of life (ADL)

- SAQ: Complexity $(\mathrm{Cx})$

The reason why these indicators are excluded from the IS Managers sub model is that they can't answer corresponding questions. Information that is purely technical e.g. ADL and $\mathrm{Cx}$ or relative to Users e.g. UC, is to be eliminated from the IS Managers survey [8]. On the other hand, IS Managers give relevant and precise information about their expertise areas such as budget allocated to hardware, documentation quality or details about the staff involved in IS.

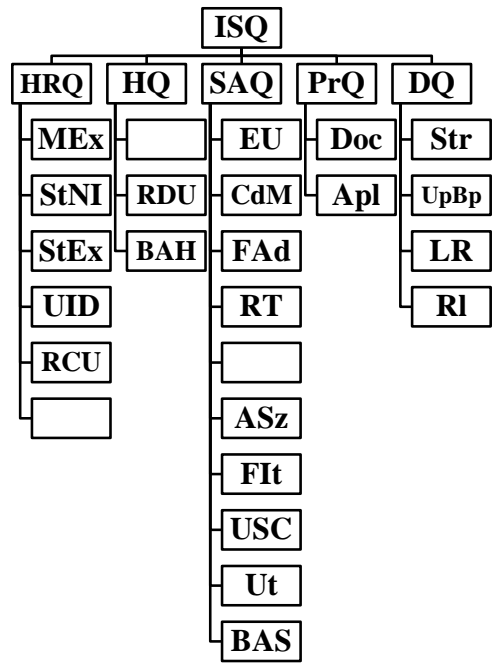

Fig. 2. Indicators Relative to IS Managers.

\section{RESEARCH METHODOLOGY}

\section{A. Study Description}

The surveys are designed in order to be adapted for each type of the questioned: IS Managers, technical staff, functional staff and users. The survey first part, regardless of type, helps to make a profile picture of the respondent, the second part deal with IS generalities, e.g. the IS department size, in numbers and staff skills or qualification. The third part emphasizes the relationship between the respondent and other IS contributors, like the difficulty met when detailing technical requirements by managers for developers. The last part of the survey is about measuring indicators concerning software/application and hardware utilization in order to see if there is a way to optimize available resources, beside software and application impact on reduction time on performing a given task and on IS contributors' efficiency. The structure above is common to the four types of surveys; nevertheless every survey has its own distinctive feature specific to the different kind of staff, subject of the inquiry.

The survey addressed to IS manager focuses on the governance side of information system like the allocated budget for IS structure, the global strategies or orientations of the firm.

\section{B. Study Implementation}

The case study is Moroccan public universities where the surveys were distributed to the IS managers and a group of technical staff during a national meeting organized within the project TEMPUS ${ }^{1}$ MISSION ${ }^{2}$ on October $29^{\text {th }}$ and $30^{\text {th }} 2015$ in Agadir Morocco. In such a context, the respondents are naturally engaged and the collected data are reliable. Data from other IS intervening were collected from each university via the IS manager and sent by email. The majority of questions contained on surveys return quantitative data, except a few questions which allow qualitative answers to help understanding and clarifying some subjects. A primary study and analyze of the surveys was presented during the closing meeting of the project on March $11^{\text {th }} 2016$ (https://goo.gl/UArq4t), and data complement was collected just shortly after by email. In the following, the aggregation of the survey questions into the model indicators will be pointed out and followed up with data analysis.

\section{Aggregation of Questions Into Indicators \\ 1) Human resources quality (HRQ)}

\section{a) Manager Experience (MEx)}

The IS quality is directly affected by the IS manager experience [17]. Decisions and strategies adopted are determining for the whole IS intervening. This indicator is measured in term of years of experience on management and IS and aggregates the questions below:

- How many years' experience on Management do you have? (ExM)

\footnotetext{
${ }^{1}$ Trans-European Mobility Program for University Studies

${ }^{2}$ Establishment of a National Service of an Operational Information System
} 
- How many years' experience on IS do you have? (ExSiM)

The variable indicator is a mean of the two variables questions as mentioned on the formula below:

MEx $=\frac{(\mathbf{E x M}+\mathbf{E x S i M})}{2}$

The levels of each variable are described in Table II.

\section{b) Staff numbers involved in IS (StNI)}

This indicator returns the number of the staff involved in IS including every one that contributes directly or indirectly on IS development, categorized by profiles, which are competence degree and IT specialization. It aggregates the questions below:

- What is the number of the following profiles composing the IS department?

- IT specialist (EfInf)

- Non IT specialist (EfNInf)

- Executives (EfCdr)

- Middle Execuives (EfCdrm)

- Technician (EfTch)

The indicator value is the mean of the weighted variables questions as indicated on the following formula:

StNI $=\frac{(2 \times \text { EfInf }+ \text { EfNInf })+(3 \times \text { EfCdr }+2 \times \text { EfCdrm }+ \text { EfTch })}{2}$

The variable questions above are subdivided on two groups, the first one divides the IS staff in two categories (IT specialist and Non IT specialist) and the second one divides the IS staff in three categories (Executives, Middle Executives and Technician). The weight of each variable question is equal to its importance degree on the group.

\section{c) IS staff experience (StEx)}

The experience accumulation of IS staff lead to a better quality of IS itself through avoiding frequent errors and reducing task's length. This indicator is measured in term of years of experience and competence degree of IS staff. It aggregates the questions below:

- What is the number of the following profiles composing the IS department?

- Staff with less than 2 years' experience (Ef2a)

- Staff with experience between 2 and 5 years (Ef2a5a)

- Staff with experience between 5 and 10 years (Ef5a10a)

- Staff with more than 10 years' experience (Ef10a)

- How do you evaluate the technical staff's skills? (CompTch)

- What is the number of functional staff? (EffFct)
- How many applications are developed by the technical staff? (NbDev)

The formula relating these variable questions to the corresponding variable indicator is as following:

$$
\begin{aligned}
\text { StEx }=\frac{1}{4} \times((E f 2 a+ & 2 \times \text { Ef } 2 a 5 a+3 \times \text { Ef5a10a }+4 \times \text { Ef10a }) \\
& +(4-\text { CompTch })+\text { EffFct }+ \text { NbDev })
\end{aligned}
$$

Since the indicator is by definition reflecting the experience degree of IS staff, the number of IS staff of each category is weighted by years of experience. The minus sign appears to conserve the logical order of the variables level (Table II). The formula above returns values included between 3 and 10 as detailed in Table I.

TABLE I. RELATING STEX COMPUTED VALUES WITH ANSWERS

\begin{tabular}{|l|l|l|l|}
\hline Variable Indicator & Interval & Value & Answers \\
\hline \multirow{4}{*}{ StEx } & ] $3,4]$ & 1 & Inexperienced \\
\cline { 2 - 4 } & ] $4,6]$ & 2 & Less Experienced \\
\cline { 2 - 4 } & ] $6,8]$ & 3 & Averagely experienced \\
\cline { 2 - 4 } & ] $8,10]$ & 4 & Experienced \\
\hline
\end{tabular}

d) Users implication degree (UID)

This indicator is measured by the number of interactions with available applications and software $[21 ; 23]$.

- Are there any unused applications? (ApNUt)

- If yes, how many unused applications are there?

(NbApNUt)

$$
\mathrm{UID}=\left\{\begin{array}{cc}
\text { NbApNUt if ApNUt }=1 \\
4 \quad \text { if ApNUt }=2
\end{array}\right\}
$$

e) Resistance to change of users (RCU)

RCU measures the adherence degree of users facing the new practices related to IS [23]. This indicator is expressed on the survey by the question below and takes the same values as those of Ad (Table II).

- What is the adherence degree of users to new information system practices? (Ad)

\section{2) Hardware quality $(H Q)$}

a) Rate of daily use

The number of hours past at using IT equipment divided by the number of daily work hours. This indicator is sorted by hardware type (computer, printer, server...). The corresponding questions are as below:

- What is the average number of hours per day spent on using hardware type i? (RDU)

\section{$i \in\left\{\right.$ computer $_{v}$ printer $_{v}$ server $_{v}$ scanner $_{v} \ldots$ \}}

\section{b) Budget allocated to hardware (BAH)}

This indicator gives an indication of the budget allocated to hardware using the question below:

- What is the portion of the budget allocated for hardware's purchase and maintenance? (BgAM) 
The proportion is used instead of the real amount to allow later comparison between organizations.

3) Software and application quality (SAQ)

a) Ease of use (EoU)

The exploitation rate of software and applications gives a numerical indication for the ease of use noted by the different players. For instance, as managers have an overview of all the software and applications available on the organization, they can answer this question thoroughly.

- What is the exploitation rate of the existing software and applications? (TExp)

\section{b) The code development maintainability (CDM)}

Maintainability of the code development allows saving time and energy, and thereby contributes on improving the IS quality [18]. The questions corresponding to this indicator are:

- Has the code been reused for other applications? (CdRut)

- If yes, specify the original application and the destination one! (ApOr1, ApDst1, ApOr2, ApDst2, ApOr3, ApDst3).

(The survey allows three possibilities for the question above).

The formula relating these variable questions to the variable indicator is as following:

$C D M=\left\{\sum_{1}^{3} \begin{array}{c}0 \text { if } \text { CdRut }=2 \\ \text { ApOri if } C d R u t=1\end{array}\right\}$

The value of the indicator CDM is set to null when the answer is that the code is not reused for other applications and it takes the sum of reused code application if the answer is yes (Table III).

\section{c) Flexibility or adaptability $(F A d)$}

The ability of software and applications to satisfy similar needs to requirements originally specified. This indicator is reported on the survey by the question below:

- Do you think that available software and applications can meet similar needs to those initially specified? (FAd)

The values of this variable indicator are the same as those of the related variable question (Table III).

\section{d) Response time $(R T)$}

The duration between the time the request is executed and the response time, this indicator is reported on the survey by the question below:

- How do you assess the software and applications response time?

This indicator is measured qualitatively and its values vary from very slow to very fast (Table III).

e) The application/software size (ASz)
The size of an application can be measured in different ways, but the most appropriate way to find out from a manager is the total time spent on programming, formulated on the survey by the question below:

- What is the total programming time for an application?

(DurT)

\section{f) Friendly interfaces(Fit)}

The interfaces should be practical and intuitive according to user's opinion. This indicator is reported on the survey by the questions below:

- $\quad$ Are the software/application interfaces friendly? (FIt)

- If no, explain why! (FItN)

The indicator takes the value of the first question and uses the answer of the second one as a clarification.

\section{g) Users specifications conformity (USC)}

Developed applications or software have to match with the requirements initially specified, this indicator is reported on the survey by the question below:

- Are the developed applications compliant with the original specifications? (USC)

The indicator takes the values: yes/ partly /no.

h) Utility (Ut)

The gap between the situations with and without the software, in terms of efficiency and work duration. This indicator is staggered from 1 "no utility" to 5 "very useful". The questions related to this indicator are:

- How useful is the application / software in terms of working time? (UtTp)

- If the application / software have not induced any change in working time, explain why! (UtTpN)

- How useful is the application / software in terms of efficiency? (UtEf)

- If the application / software have not induced any change in efficiency, explain why! (UtEfN)

The formula aggregating the variables question into variable indicator is as below:

$\mathbf{U t}=\frac{(\mathrm{UtTp}+\mathrm{UtEf})}{\mathbf{2}}$

It is to be noted that the variables question UtTpN and UtEfN are qualitative and their roles is limited to enlighten why the introduction of software and applications didn't produce any positive impact in terms of efficiency and work duration.

\section{i) Budget allocated to software and application (BAS)}

The proportion of the annual budget spent on new software and/or on application development.

- How much software were acquired? (NbLog) 
- What is the portion of the budget allocated for software's purchase? (BgLog)
- What is the portion of the budget allocated for staff training involved on the Information system? (BgPSI)

TABLE II. RELATING QUESTION VARIABLES ON MANAGERS SURVEY TO HUMAN RESOURCES QUALITY INDICATOR VARIABLES

\begin{tabular}{|c|c|c|c|c|c|}
\hline Variables indicator & Answers & Values & Variables question & Answers & Values \\
\hline \multirow{8}{*}{ MEX } & \multirow{2}{*}{ Inexperienced } & \multirow{2}{*}{ 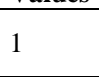 } & \multirow[t]{4}{*}{ P } & Less than 2 years & 1 \\
\hline & & & & Between 2 and 5 years & 2 \\
\hline & \multirow{2}{*}{ Less Experienced } & \multirow{2}{*}{2} & & Between 5 and 10 years & 3 \\
\hline & & & & More than 10 years & 4 \\
\hline & \multirow{2}{*}{ Averagely experienced } & \multirow{2}{*}{3} & \multirow{4}{*}{ ExSiM } & Less than 2 years & 1 \\
\hline & & & & Between 2 and 5 years & 2 \\
\hline & \multirow{2}{*}{ Experienced } & \multirow{2}{*}{4} & & Between 5 and 10 years & 3 \\
\hline & & & & More than 10 years & 4 \\
\hline \multirow{15}{*}{ StNI } & \multirow{5}{*}{ Small number } & \multirow{5}{*}{1} & \multirow{3}{*}{ EfInf } & Less than 5 persons & 1 \\
\hline & & & & Between 5 and 10 persons & 2 \\
\hline & & & & More than 10 persons & 3 \\
\hline & & & \multirow{3}{*}{ EfNInf } & Less than 5 persons & 1 \\
\hline & & & & Between 5 and 10 persons & 2 \\
\hline & \multirow{5}{*}{ Average number } & \multirow{5}{*}{2} & & More than 10 persons & 3 \\
\hline & & & \multirow{3}{*}{ EfCdr } & Less than 5 persons & 1 \\
\hline & & & & Between 5 and 10 persons & 2 \\
\hline & & & & More than 10 persons & 3 \\
\hline & & & \multirow{3}{*}{ EfCdrm } & Less than 5 persons & 1 \\
\hline & & & & Between 5 and 10 persons & 2 \\
\hline & & & & More than 10 persons & 3 \\
\hline & Sufficient number & 3 & & Less than 5 persons & 1 \\
\hline & & & EfTch & Between 5 and 10 persons & 2 \\
\hline & & & & More than 10 persons & 3 \\
\hline & & & & Less than 5 persons & $\begin{array}{ll}3 \\
1\end{array}$ \\
\hline & & & Ef2a & Between 5 and 10 persons & 2 \\
\hline & Inexperienced & 1 & & More than 10 persons & 3 \\
\hline & & & & Less than 5 persons & $\begin{array}{ll}3 \\
1\end{array}$ \\
\hline & & & Ef2a5a & Between 5 and 10 persons & 2 \\
\hline & & & & More than 10 persons & 3 \\
\hline & & & & Less than 5 persons & $\begin{array}{ll}0 \\
1\end{array}$ \\
\hline & & & Ef5a10a & Between 5 and 10 persons & 2 \\
\hline & Less Experienced & 2 & & More than 10 persons & 3 \\
\hline StEx & & & & High skills & 1 \\
\hline & & & CompTch & Average skills & 2 \\
\hline & & & & Low skills & 3 \\
\hline & & & & Less than 5 persons & $\begin{array}{ll}0 \\
1\end{array}$ \\
\hline & Averagely experienced & 3 & EffFct & Between 5 and 10 persons & 2 \\
\hline & & & & More than 10 persons & 3 \\
\hline & & & & None & $\begin{array}{ll}0 \\
1\end{array}$ \\
\hline & & & & Between 1 and 5 app & 2 \\
\hline & Experienced & 4 & NbDev & Between 5 and 10 app & 3 \\
\hline & & & & More than 10 app & 4 \\
\hline & No implication & 1 & & Yes & 1 \\
\hline & Low implication & 2 & ApNUt & No & 2 \\
\hline UID & & & & More than 10 & 1 \\
\hline & Average implication & 3 & NbApNUt & {$[5,10[$} & $\frac{1}{2}$ \\
\hline & High implication & 4 & & {$[1,5[$} & 3 \\
\hline & No adherence & 1 & & No adherence & 1 \\
\hline & Low adherence & 2 & & Low adherence & 2 \\
\hline $\mathrm{RCU}$ & Average adherence & 3 & $\mathrm{Ad}$ & Average adherence & 3 \\
\hline & High adherence & 4 & & High adherence & 4 \\
\hline
\end{tabular}

The variable indicator is a mean of the three variables question above and its values are reported in Table III.

BAS $=\frac{(\text { NbLog }+ \text { BgLog }+ \text { BgPSI })}{3}$

4) Procedures quality $(\operatorname{Pr} Q)$

a) Documentation (Doc)
Documentation quality on the literature review refers to the documentation accompanying a software development [3], whereas the indicator Doc in our model reflects one side of procedures quality.

The indicator Doc is reported on the survey by the four questions below:

- Does your organization have an information system blueprint? (SDSI) 
- Are there procedures for information system in your organization?(PrSI)

- Is there a specific documentation for IS procedures? (DocSI)

- Is there an entity responsible for production, updating, archiving, etc. of this documentation? (EnDoc)

\section{Doc $=\frac{(\text { SDSI }+ \text { PrSI }+ \text { DocSI }+ \text { EnDoc })}{4}$}

This indicator is staggered from "compliant" when all the quality attributes exist to "non-existent" where they are all absent (Table III).

TABLE III. RELATING QUESTION VARIABLES ON MANAGER SURVEY TO SOFTWARE/APPLICATION, PROCEDURE AND DATA QUALITY INDICATOR VARIABLES

\begin{tabular}{|c|c|c|c|c|c|}
\hline Variables indicator & Answers & Values & Variables question & Answers & Values \\
\hline \multirow{6}{*}{$\mathrm{EoU}$} & Very difficult to use & 0 & \multirow{6}{*}{ TExp } & {$[0 \%, 25 \%]$} & 1 \\
\hline & Difficult to use & 1 & & {$[25 \%, 50 \%]$} & 2 \\
\hline & Moderately difficult & 2 & & \multirow{2}{*}[50\%,75\%]{} & \multirow{2}{*}{3} \\
\hline & Moderately easy & 3 & & & \\
\hline & Easy to use & 4 & & \multirow{2}{*}[75\%,100\%]{} & \multirow{2}{*}{4} \\
\hline & too easy to use & 5 & & & \\
\hline \multirow{4}{*}{$\mathrm{CDM}$} & Not maintainable & 0 & \multirow{2}{*}{ CdRut } & Yes & 1 \\
\hline & Maintainable 1 & 1 & & No & 2 \\
\hline & Maintainable 2 & 2 & $\Delta \mathrm{nOri}$ & Blank & 0 \\
\hline & Maintainable 3 & 3 & ApUI1 & Filled & 1 \\
\hline \multirow{2}{*}{ FAd } & Yes & 1 & \multirow{2}{*}{ FAd } & Yes & 1 \\
\hline & No & 2 & & No & 2 \\
\hline \multirow{5}{*}{ RT } & Very slow & 1 & \multirow{5}{*}{ RT } & Very slow & 1 \\
\hline & Slow & 2 & & Slow & 2 \\
\hline & Average & 3 & & Average & 3 \\
\hline & Fast & 4 & & Fast & 4 \\
\hline & Very fast & 5 & & Very fast & 5 \\
\hline \multirow{4}{*}{$\mathrm{ASz}$} & Small & 1 & \multirow{4}{*}{ DurT } & Small & 1 \\
\hline & Medium & 2 & & Medium & 2 \\
\hline & Large & 3 & & Large & 3 \\
\hline & Very large & 4 & & Very large & 4 \\
\hline \multirow{3}{*}{ FIt } & Yes & 1 & \multirow{2}{*}{ FIt } & Yes & 1 \\
\hline & \multirow{2}{*}{ No } & \multirow{2}{*}{2} & & No & 2 \\
\hline & & & FItN & \multicolumn{2}{|l|}{ Qualitative } \\
\hline \multirow{12}{*}{ Ut } & \multirow{2}{*}{ No utility } & \multirow{2}{*}{1} & \multirow{5}{*}{ UtTp } & No utility & 1 \\
\hline & & & & Low utility & 2 \\
\hline & & 2 & & Average utility & 3 \\
\hline & Low utility & 2 & & Useful & 4 \\
\hline & & & & Very Useful & 5 \\
\hline & & & UtTpN & Qualitative & \\
\hline & Average utility & 3 & & No utility & 1 \\
\hline & & & & Low utility & 2 \\
\hline & Useful & 4 & UtEf & Average utility & 3 \\
\hline & Useful & 4 & & Useful & 4 \\
\hline & Very Usful & 5 & & Very Usful & 5 \\
\hline & very Usful & 3 & UtEfN & Qualitative & \\
\hline & & & & {$[0,1]$} & 1 \\
\hline & Insufficient & 1 & NbLog & {$[1,4]$} & 2 \\
\hline & & & & More than 5 & 3 \\
\hline & & & & Less than $0,1 \%$ & 1 \\
\hline BAS & Moderate & 2 & BgLog & ] $0,1 \%, 10 \%[$ & 2 \\
\hline & & & & More than $10 \%$ & 3 \\
\hline & & & & Less than $0,1 \%$ & 1 \\
\hline & Sufficient & 3 & BgPSI & ] $0,1 \%, 10 \%[$ & 2 \\
\hline & & & & More than $10 \%$ & 3 \\
\hline Doc & Compliant & 1 & SDSI & Yes & 1 \\
\hline
\end{tabular}




\begin{tabular}{|c|c|c|c|c|c|}
\hline & & & & No & 2 \\
\hline & & & \multirow{2}{*}{ PrSI } & Yes & 1 \\
\hline & \multirow{2}{*}{ Non-compliant } & \multirow{2}{*}{2} & & No & 2 \\
\hline & & & \multirow{2}{*}{ DocSI } & Yes & 1 \\
\hline & \multirow{3}{*}{ Non existent } & \multirow{3}{*}{3} & & No & 2 \\
\hline & & & \multirow{2}{*}{ EnDoc } & Yes & 1 \\
\hline & & & & No & 2 \\
\hline \multirow{6}{*}{ Apl } & \multirow{2}{*}{ Applicable } & \multirow{2}{*}{1} & \multirow{3}{*}{ AplPr } & Applicable & 1 \\
\hline & & & & Partly applicable & 2 \\
\hline & Partly applicable & 2 & & Not Applicable & 3 \\
\hline & \multirow{3}{*}{ Not Applicable } & \multirow{3}{*}{3} & \multirow{3}{*}{ PrRap } & Yes & 1 \\
\hline & & & & Partly & 2 \\
\hline & & & & No & 3 \\
\hline \multirow{8}{*}{ RI } & \multirow{2}{*}{ No relevance } & \multirow{2}{*}{1} & \multirow{4}{*}{ Ind } & 0 & 1 \\
\hline & & & & {$[1,5[$} & 2 \\
\hline & \multirow{2}{*}{ Low relevance } & \multirow{2}{*}{2} & & {$[5,10[$,} & 3 \\
\hline & & & & More than 10 & 4 \\
\hline & \multirow{2}{*}{ Average relevance } & \multirow{2}{*}{3} & \multirow{4}{*}{ Res } & 0 & 1 \\
\hline & & & & {$[1,5[$} & 2 \\
\hline & \multirow{2}{*}{ High relevance } & \multirow{2}{*}{4} & & {$[5,10[$,} & 3 \\
\hline & & & & More than 10 & 4 \\
\hline
\end{tabular}

\section{b) Applicability (Apl)}

The quality of the procedures depends on their applicability by the IS intervening. This indicator is staggered from 1: "applicable" to 3: "not applicable" and aggregates the two questions below:

- What is the applicability degree of the procedures by the Information System intervening? (AplPr)

- Is there any tangible impact of the procedures on the speed of daily tasks? (PrRap)

$$
\text { Apl }=\frac{(\text { AplPr }+ \text { PrRap })}{2}
$$

5) Data quality $(D Q)$ : The quality of data is a "multidimensional measure of the suitability of data to fulfill the purpose bound in its acquisition/generation. This suitability may change over time as needs change' ' $3 ; 4]$. This underlines the subjective requirements for data quality in respective institutions and illustrates a possible dynamic data quality process. The definition makes it clear that "the quality of data depends on the time of the consideration and on the level of claims placed at the time on the data'.

\section{a) Structure(Str)}

- Are the data stored in a DBMS?

\section{b) Updating and back up(UpBp)}

- What is the time interval between two backups?

c) Lack of redundancy $(L R)$

- Are there any data redundancies?

d) Relevance ( $R I)$

- What is the number of indicators serving the objectives drawn by the University? (Ind)
- What is the number of expected results from these indicators? (Res)

$\mathbf{R I}=\frac{(\text { Ind }+ \text { Res })}{2}$

\section{DATA ANALYSIS AND RESUltS}

Data analysis was performed through three phases. First, row data from the IS Managers survey were gathered by indicator. Second, the aggregation formulas were used to give the indicators numerical values. Third, a standardization of all values was performed in order to have summarized value for each component and to compare later between the universities subject of the study. It should be noted that because of length restriction, only HRQ and DQ dimensions will be analyzed on the following.

\section{A. Indicator Quantification}

The central objective of the model ISysQ is to have numerical values for every indicators, components and finally for the ISQ as a whole. Table IV gives indicator values computed from data collected via the survey designed for IS managers of Moroccan public universities, and then aggregated by the formulas defined previously.

The range of the indicator Manager Experience (MEx) is from Inexperienced (coded as 1) to Experienced (coded as 4) (Table 5.1.), it's noted that UAE and UIT have the highest value concerning this indicator.

Focusing on the remaining indicators of HRQ lead to a finding that for each one there is a different university that has the highest level, so it's not possible nor to compare Universities according to all HRQ indicators simultaneously and determine the university with the highest level of HRQ, neither to aggregate the indicator values on one value for HRQ because of indicators range difference, thus the necessity to have comparable values for all the indicators. 
TABLE IV. INDICATOR VALUE BY UNIVERSITY

\begin{tabular}{|c|c|c|c|c|c|c|c|c|c|}
\hline \multirow{2}{*}{ University } & \multicolumn{5}{|l|}{ HRQ } & \multicolumn{4}{|l|}{ DQ } \\
\hline & $M E x$ & StNI & StEx & UID & $R C U$ & Str & $U p B p$ & $L R$ & $R I$ \\
\hline USMBA & 3,5 & 8 & 5 & 3 & 3,67 & 2 & 3 & 2 & 3,67 \\
\hline UMP & 3,5 & 9 & 4,75 & 3 & 2,67 & 2 & 3 & 2 & 2,17 \\
\hline UIZ & 1 & 5,5 & 4,5 & 3 & 3,67 & 2 & 3 & 2 & 1 \\
\hline USMS & 3,5 & 4,5 & 3,75 & 3 & 2,67 & 1 & 1 & 1 & 2,17 \\
\hline UAE & 4 & 7 & 5 & 3 & 2 & 2 & 1 & 2 & 2 \\
\hline UIT & 4 & 9 & 5,25 & 4 & 3,33 & 2 & 1 & 2 & 3,33 \\
\hline UMI & 2,5 & 5,5 & 4,5 & 3 & 3 & 2 & 1 & 1 & 1 \\
\hline UCD & 3,5 & 7 & 5 & 4 & 2,67 & 2 & 3 & 2 & 2,5 \\
\hline UHI & 3,5 & 7 & 5,5 & 3 & 4 & 2 & 3 & 2 & 3 \\
\hline UMV & 3 & 8,5 & 4,75 & 3 & 3 & 2 & 1 & 1 & 2,33 \\
\hline UHIIC & 2,5 & \begin{tabular}{|l|}
8, \\
8
\end{tabular} & 5,25 & 3 & 3 & 2 & 1 & 1 & 2 \\
\hline UCA & 2,5 & 6 & 5 & 4 & 3,33 & 2 & 2 & 2 & 3 \\
\hline
\end{tabular}

TABLE V. TABLE 1.1. INDICATOR LEVEL OF HRQ SUB MODEL BY UNIVERSITY

\begin{tabular}{|l|l|l|l|l|l|}
\hline University & MEx & StNI & StEx & UID & RCU \\
\hline USMBA & Averagely experienced & Average number & Less Experienced & Average implication & Average adherence \\
\hline UMP & Averagely experienced & Average number & Less Experienced & Average implication & Low adherence \\
\hline UIZ & Inexperienced & Average number & Less Experienced & Average implication & Average adherence \\
\hline USMS & Averagely experienced & Small number & Inexperienced & Average implication & Low adherence \\
\hline UAE & Experienced & Average number & Less Experienced & Average implication & Low adherence \\
\hline UIT & Experienced & Average number & Less Experienced & High implication & Average adherence \\
\hline UMI & Less Experienced & Average number & Less Experienced & Average implication & Average adherence \\
\hline UCD & Averagely experienced & Average number & Less Experienced & High implication & Low adherence \\
\hline UHI & Averagely experienced & Average number & Less Experienced & Average implication & High adherence \\
\hline UMV & Averagely experienced & Average number & Less Experienced & Average implication & Average adherence \\
\hline UHIIC & Less Experienced & Average number & Less Experienced & Average implication & Average adherence \\
\hline UCA & Less Experienced & Average number & Less Experienced & High implication & Average adherence \\
\hline
\end{tabular}

TABLE 5.2. INDICATOR LEVEL OF DQ SUB MODEL BY UNIVERSITY

\begin{tabular}{|c|c|c|c|c|}
\hline University & Str & UpBp & LR & RI \\
\hline USMBA & Structured & short & checked & High relevance \\
\hline UMP & Structured & short & checked & Average relevance \\
\hline UIZ & Structured & short & checked & No relevance \\
\hline USMS & Not Structured & depending & Not checked & Average relevance \\
\hline UAE & Structured & depending & checked & Low relevance \\
\hline UIT & Structured & depending & checked & High relevance \\
\hline UMI & Structured & depending & Not checked & No relevance \\
\hline UCD & Structured & short & checked & Average relevance \\
\hline UHI & Structured & short & checked & Average relevance \\
\hline UMV & Structured & depending & Not checked & Average relevance \\
\hline UHIIC & Structured & depending & Not checked & Low relevance \\
\hline UCA & Structured & long & checked & Average relevance \\
\hline
\end{tabular}

\section{B. Values Standardization}

Given the inability to compare indicators with the actual values, standardization is required. Standardization is the process of putting different variables on the same scale. This process allows comparing scores between different types of variables. Typically, to standardize variables, the mean and standard deviation must be computed for a variable. Then, for each observed value of the variable, the mean is subtracted and divided by the standard deviation.
Tables 6.1 and 6.2 gives standardized values for HRQ and DQ indicators according to the method described above, the last column contains aggregated value of the components where the value that takes the component is the mean of standardized values of indicators constituting it.

It can be noticed from data in Tables 6.1 and 6.2 that indicators values become comparable and the component value provide a summarized information about the quality state of the IS component. 
TABLE VI. TABLE 2.1. STANDARDIZED INDICATOR VALUE OF HRQ BY UNIVERSITY

\begin{tabular}{|c|c|c|c|c|c|c|}
\hline University & MEx & StNI & StEx & UID & $\mathbf{R C U}$ & HRQ \\
\hline USMBA & 0,51 & 0,65 & 0,33 & $-0,58$ & 1,11 & 0,41 \\
\hline UMP & 0,51 & 1,36 & $-0,24$ & $-0,58$ & $-0,78$ & 0,05 \\
\hline UIZ & $-2,56$ & $-1,12$ & $-0,81$ & $-0,58$ & 1,11 & $-0,79$ \\
\hline USMS & 0,51 & $-1,83$ & $-2,52$ & $-0,58$ & $-0,78$ & $-1,04$ \\
\hline UAE & 1,13 & $-0,06$ & 0,33 & $-0,58$ & $-2,05$ & $-0,24$ \\
\hline UIT & 1,13 & 1,36 & 0,90 & 1,73 & 0,46 & 1,12 \\
\hline UMI & $-0,72$ & $-1,12$ & $-0,81$ & $-0,58$ & $-0,16$ & $\begin{array}{l}-0,68 \\
\end{array}$ \\
\hline UCD & 0,51 & $-0,06$ & 0,33 & 1,73 & $-0,78$ & $\mathbf{0 , 3 5}$ \\
\hline UHI & 0,51 & $-0,06$ & 1,47 & $-0,58$ & 1,73 & 0,62 \\
\hline UMV & $-0,10$ & 1,00 & $-0,24$ & $-0,58$ & $-0,16$ & $-0,01$ \\
\hline UHIIC & $-0,72$ & 0,65 & 0,90 & $-0,58$ & $-0,16$ & $\mathbf{0 , 0 2}$ \\
\hline UCA & $-0,72$ & $-0,77$ & 0,33 & 1,73 & 0,46 & 0,21 \\
\hline Mean & 3,08 & 7,08 & 4,85 & 3,25 & 3,08 & \\
\hline SD & 0,81 & 1,41 & 0,44 & 0,43 & $\mathbf{0 , 5 3}$ & \\
\hline
\end{tabular}

TABLE 6.2. STANDARDIZED INDICATOR VALUE OF DQ BY UNIVERSITY

\begin{tabular}{|c|c|c|c|c|c|}
\hline University & Str & UpBp & LR & RI & DQ \\
\hline USMBA & 0,30 & 1,14 & 0,71 & 1,67 & 0,95 \\
\hline UMP & 0,30 & 1,14 & 0,71 & $-0,22$ & 0,48 \\
\hline UIZ & 0,30 & 1,14 & 0,71 & $-1,70$ & 0,11 \\
\hline USMS & $-3,32$ & $-0,96$ & $-1,41$ & $-0,22$ & $-1,48$ \\
\hline UAE & 0,30 & $-0,96$ & 0,71 & $-0,44$ & $-0,10$ \\
\hline UIT & 0,30 & $-0,96$ & 0,71 & 1,24 & 0,32 \\
\hline UMI & 0,30 & $-0,96$ & $-1,41$ & $-1,70$ & $-0,94$ \\
\hline UCD & 0,30 & 1,14 & 0,71 & 0,19 & 0,58 \\
\hline UHI & 0,30 & 1,14 & 0,71 & 0,82 & 0,74 \\
\hline UMV & 0,30 & $-0,96$ & $-1,41$ & $-0,02$ & $-0,52$ \\
\hline UHIIC & 0,30 & $-0,96$ & $-1,41$ & $-0,44$ & $-0,63$ \\
\hline UCA & 0,30 & 0,09 & 0,71 & 0,82 & 0,48 \\
\hline Mean & 1,92 & 1,92 & 1,67 & 2,35 & \\
\hline SD & 0,28 & 0,95 & 0,47 & 0,79 & \\
\hline
\end{tabular}

\section{DISCUSSION}

\section{A. Comparing Universities According to the IS Component "Human Resources (HR)"}

Among the twelve Moroccan public universities, UIT is the best in term of HRQ according to IS managers, with a score of 1,12 , while USMS has the lowest HRQ score $(-1,04)$. Let's take the case of two universities that have sores close to the mean: UHIIC $(0,02)$ and UMV $(-0.01)$, and try to pursue steps to an inclusive comparison. First of all, when taking the qualitative attributes of HRQ indicators, it is found that all indicators of the two universities have the same values except the first one (MEx) which value for UHIIC is less than this for UMV (Table 5.1). Yet, it's inconsistent with the fact that HRQ value for UHIIC is greater than this of UMV. So, the second step is to take row values that were computed from the aggregating formulas (Table IV) and one found that besides UID and RCU that have the same values for the two universities, MEx and StNI have greater values for UMV than for UHIIC (MEx $(3 ; 2,5)$, StNI $(8,5 ; 8))$ and a less one for StEx $(4,75 ; 5,25)$. Once again, it can't be determined from this whose HRQ value is greater than the other because each indicator follows a different scale. Third step is about comparing standardized values that take into consideration the scale of each indicator and make the difference between the values of the same indicators for the two universities comparable. In Table 6.1, it can be noticed that even if HRQ is better in UHIIC than in UMV, UMV is better in MEx and StNI with respective differences 0,62 and 0,35.

As a conclusion, one can say that HRQ in UHIIC is globally better than this of UMV. However, MEx and StNI in UHIIC have a low performance than those of UMV.

\section{B. Comparing Universities According to the IS Component "Data"}

USMBA is the best university in term of DQ among the twelve Moroccan public universities according to IS managers, with a score of 0,95 , while USMS has the lowest DQ score $(-1,48)$. As it's already done for HRQ, one take the case of two universities that have sores close to the mean: UIZ $(0,11)$ and UAE $(-0,10)$, and try to pursue steps to an inclusive comparison. First of all, taking the qualitative attributes of DQ indicators (Table 5.2.), it's found that two out of four indicators have the same values for the two universities. For the other ones, Updating and Back up (UpBp) value is greater in UIZ than in UAE (Short, Depending on data sensitivity and application type) contrary to Relevance (RI) value which is less in UIZ than in UAE. The contrast between the two universities doesn't allow a global comparison of DQ. So, the second step is about taking row values that were computed 
from the aggregating formulas (Table IV) and it's found that besides Str and LR that have the same values for the two universities, $\mathrm{UpBp}$ has a greater value for UIZ than for UAE $\mathrm{UpBp}(3 ; 1)$ and a less one for RI $(1 ; 2)$. Once again, it can't be determined from the former whose DQ value is greater than the other because each indicator has a different range. Third step is about comparing standardized values that take into consideration the range of each indicator and make the difference between the values of the same indicators comparable. In Table 6.2, it is noticed that even if DQ is better in UIZ than in UAE, UAE is better in UpBp with a difference of 0,26 .

As a conclusion, one can say that DQ in UIZ is globally better than this of UAE. Nevertheless, RI in UIZ has a low performance than this of UAE.

\section{CONCLUSION}

This study makes two important contributions to research on Information System Quality. The first novel aspect of this model is that it allows having numerical values for all indicators instead of qualitative description. These numerical values contribute to give each IS component standardized values able to provide an objective measure and an unbiased comparison.

Second, the findings provide scaled values of all the model indicators and components, thus enabling to arrange IS component of an organization from the lowest to the highest component performance. Thereafter a particular attention is given to the components with less performance level and go down to the indicators that compose them in order to highlight those with low values. Here one can point out precisely the weaknesses of ISQ in the organization, and can therefore propose corrective measures.

The data used in our research are collected from IS managers while data required to complete the whole picture of ISQ on an organization is from all IS intervening who are in addition to IS managers, technical staff, functional staff and users. As future research that are partly underway, once data from all IS intervening are collected, the same steps of the present study will be followed, leading to numerical values of all ISQ indicators and components. Thereafter, an aggregation of all IS intervening perspectives must be performed by organization entailing this way, one summarized value of ISQ for a specific organization that permits objective comparison.

\section{REFERENCES}

[1] Aouhassi, S., \& Hanoun, M. (2015). Information System Quality: State of the Art and New Model. International Journal of Engineering Research and Technology, 4(03), 589-594.

[2] Aouhassi, S., \& Hanoune, M. (2018). Information system qualification by component. In ACM International Conference Proceeding Series (Vol. Part F1353). https://doi.org/10.1145/3178461.3178478

[3] Arthur, J. D. (n.d.). Assessing the Adequacy of Documentation Through Document Quality Indicators*.

[4] Azeroual, O., Gunter Saake, B., Jü rgen Wastl, B., Azeroual Azeroual, O., Gunter Saake, dzhweu, \& Wastl JuergenWastl, J. (n.d.). Data measurement in research information systems: metrics for the evaluation of data quality. Scientometrics. https://doi.org/10.1007/s11192-018$2735-5$
[5] Bakota, T., Beszédes, Á., Ferenc, R., \& Gyimóthy, T. (2008). Continuous Software Quality Supervision Using SourceInventory and Columbus, 1-2.

[6] Chawla, S. (2013). Review of MOOD and QMOOD metric sets, 3(3), 448-451.

[7] Cyra, L., \& Gorski, J. (2011). \{SCF $\}$ - A framework supporting achieving and assessing conformity with standards. Computer Standards \& Interfaces. https://doi.org/http://dx.doi.org/10.1016/j.csi.2010.03.007

[8] Dimitrios, N. K., Sakas, D. P., \& Vlachos, D. S. (2013). The Role of Information Systems in Creating Strategic Leadership Model. Procedia Social and Behavioral Sciences, 73, 285-293. https://doi.org/10.1016/j.sbspro.2013.02.054

[9] Gencel, C., Petersen, K., Ahmad, A., \& Imran, M. (2013). The Journal of Systems and Software A decision support framework for metrics selection in goal-based measurement programs: GQM-DSFMS. The Journal of Systems \& Software, 86(12), 3091-3108. https://doi.org/10.1016/j.jss.2013.07.022

[10] Gorla, N., \& Lin, S.-C. (2010). Determinants of software quality: A survey of information systems project managers. Information and $\begin{array}{lll}\text { Software } & \text { Technology, } & \text { 52(6), }\end{array}$ https://doi.org/10.1016/j.infsof.2009.11.012

[11] Heidari, F., \& Loucopoulos, P. (2014). Quality evaluation framework (QEF): Modeling and evaluating quality of business processes. International Journal of Accounting Information Systems, 15(3), 193223. https://doi.org/10.1016/j.accinf.2013.09.002

[12] Letouzey, J.-L., \& Coq, T. (n.d.). The «SQALE» Analysis Model An analysis model compliant with the representation condition for assessing the Quality of Software Source Code.

[13] Letouzey, J. L., \& Ilkiewicz, M. (2012). Managing technical debt with the SQALE method. IEEE Software, 29(6), 44-51. https://doi.org/10.1109/MS.2012.129

[14] Marinescu, R. (n.d.). Detection Strategies: Metrics-Based Rules for Detecting Design Flaws.

[15] Mordal-Manet, K., Laval, J., Ducasse, S., Anquetil, N., Balmas, F., Bellingard Laurent Bouhier, F., ... McCabe, T. J. (n.d.). An empirical model for continuous and weighted metric aggregation.

[16] Nagendra, A., \& Deshpande, M. (2014). Human Resource Information Systems (HRIS) in HR Planning and Development in Mid to Large Sized Organizations. Procedia - Social and Behavioral Sciences, 133, 61-67. https://doi.org/10.1016/j.sbspro.2014.04.169

[17] Nieves Pérez-Aróstegui, M., Bustinza-Sánchez, F., \& Barrales-Molina, V. (2015). Exploring the relationship between information technology competence and quality management. Cuadernos de Economía y Dirección de La Empresa, 18, 4-17. https://doi.org/10.1016/j.brq.2013.11.003

[18] Rothenberger, M. A., Kao, Y.-C., \& Wassenhove, L. N. Van. (2010). Total quality in software development: An empirical study of quality drivers and benefits in Indian software projects. Information \& Management, 47, 372-379. https://doi.org/10.1016/j.im.2010.10.001

[19] Sarrab, M., \& Hussain Rehman, O. M. (2014). Empirical study of open source software selection for adoption, based on software quality characteristics. ADVANCES IN ENGINEERING SOFTWARE, 69, 111. https://doi.org/10.1016/j.advengsoft.2013.12.001

[20] Shah, M. (2014). Impact of management information systems (MIS) on school administration: What the literature says. Procedia - Social and Behavioral Sciences, 116, 2799-2804. https://doi.org/10.1016/j.sbspro.2014.01.659

[21] Suzila Kassim, E., Fatiany Abdul Kader Jailani, S., Hairuddin, H., \& Hamiza Zamzuri, N. (2012). Information system acceptance and user satisfaction: The mediating role of trust. Procedia -Social and Behavioral Sciences, 57, 412-418. https://doi.org/10.1016/j.sbspro.2012.09.1205

[22] Zahedi, F. (2003). Quality Information Systems. Encyclopedia of Information Systems, 3, 631-646. https://doi.org/http://dx.doi.org/10.1016/B0-12-227240-4/00145-3

[23] Zheng, Y., Zhao, K., \& Stylianou, A. (n.d.). The impacts of information quality and system quality on users' continuance intention in information-exchange virtual communities: An empirical investigation. https://doi.org/10.1016/j.dss.2012.11.008 